\title{
Review Article \\ Collagen XVII: A Shared Antigen in Neurodermatological Interactions?
}

\begin{abstract}
Allan Seppänen
Vanha Vaasa Hospital, 65380 Vaasa, Finland

Correspondence should be addressed to Allan Seppänen; aoseppanen@gmail.com

Received 17 April 2013; Accepted 19 June 2013

Academic Editor: Carlos Barcia

Copyright (C) 2013 Allan Seppänen. This is an open access article distributed under the Creative Commons Attribution License, which permits unrestricted use, distribution, and reproduction in any medium, provided the original work is properly cited.

Collagen XVII is a nonfibril-forming transmembrane collagen, which functions as both a matrix protein and a cell-surface receptor. It is particularly copious in the skin, where it is known to be a structural component of hemidesmosomes. In addition, collagen XVII has been found to be present in the central nervous system, thus offering an explanation for the statistical association between bullous pemphigoid, in which autoimmunity is directed against dermal collagen XVII, and neurological diseases. In support of the hypothesis that collagen XVII serves as a shared antigen mediating an immune response between skin and brain, research on animal and human tissue, as well as numerous epidemiological and case studies, is presented.
\end{abstract}

\section{Introduction}

Collagens, the most abundant protein in the human body [1], are a family of extracellular or transmembrane proteins defined by a triple helical structure, which is formed by hydrogen bonds between three polypeptide strands called $\alpha$ chains [2]. Collagens have previously been overlooked for roles in the brain, since fibrillar collagens, the best known subfamily of collagens, are not present in the mature central nervous system (CNS), except in marginal structures such as the meninges [3] and the basement membrane in the bloodbrain barrier [4]. However, gradually accumulated evidence has made it apparent that collagens are not merely structural proteins giving strength to tissue, but bioactive molecules with a dynamic role within the nervous system $[5,6]$. In fact, a role in the CNS, albeit often transient, has now been identified for nearly every type of collagen during some phase of CNS development. Decisive functions, such as establishment of brain architecture [7], neuronal differentiation [8], regulation of axonal outgrowth [9] and targeting [10], and synaptic differentiation [11], have been attributed to different collagens during various stages of neural maturation $[5,12]$.

\section{Molecular Structure and Expression of Collagen XVII}

Collagen XVII, also known as bullous pemphigoid antigen 2 (BPAG2) or BP180, due to its $180 \mathrm{kDa}$ mass, belongs to the subfamily of non-fibril-forming transmembrane collagens, all four members of which function as both matrix proteins and cell-surface receptors. These proteins exist in two different forms, one being a type II-oriented transmembrane protein and the other being a shorter soluble molecule derived by posttranslational proteolysis [13, 14].

The structure of collagen XVII and its binding ligands have been previously described in detail $[14,15]$. It is a homotrimer of three $180 \mathrm{kDa} \alpha$-chains, each with a long intracellular $\mathrm{N}$-terminal domain, a short transmembrane stretch, and an extracellular C-terminus [16]. Collagen XVII is known to be a structural component of hemidesmosomes, which mediate adhesion of epidermal keratinocytes and certain other epithelial cells to the underlying basement membrane. The intracellular component of collagen XVII interacts with the $\beta 4$-integrin subunit, plectin, and BPAG1 $[17,18]$ to form a stable attachment of hemidesmosomes to 
keratin intermediate filaments within the cell. The $120-\mathrm{kDa}$ ectodomain of collagen XVII binds to both the $\alpha 6$ integrin subunit [19] and laminin 332 and is shed from the cell surface by the metalloproteases ADAM 9 and ADAM 10 [20], yielding a soluble form of the molecule into the extracellular matrix [21,22]. Although the physiological implications of the shedding are not certain, it has been proposed that this allows the anchored cell to detach, migrate, and differentiate during morphogenesis and during regeneration in wound healing $[15,23]$.

In the nervous system, collagen XVII has been studied in both animal and human studies. In bovine and rat tissue it has been detected, often colocalizing with its epithelial ligand BPAG1 and complexing with various laminins, in Muller glial cells, photoreceptors and synaptic regions of the retina, and the cerebellum [24]. In human brain tissue, collagen XVII has been shown to localize predominantly to the soma and proximal axons of neurons, the level of expression varying from one brain structure to another; areas with a strong presence of collagen XVII are the hypoglossal nucleus (nucleus XII), oculomotor nucleus (nucleus III), nucleus basalis of Meynert, supraoptic nucleus, subthalamic nuclei, and pyramidal cells of the hippocampal regions CA 4-2 and the ganglionic layer of the cerebral cortex, particularly Betz cells $[25,26]$. On an intracellular level, collagen XVII seems to be concentrated in irregularly-shaped autofluorescent granules around the nucleus, which, using electron microscopy, have been confirmed to be lipofuscin [27].

\section{Collagen XVII, Bullous Pemphigoid, and Neurological Disease}

Lack of collagen XVII or the loss of its function results in diminished epidermal adhesion and skin blistering in response to minimal shearing forces. In non-Herlitz-type junctional epidermolysis bullosa this can be caused by mutations in the gene coding collagen XVII, COL17A1 [28]; in the pemphigoids, that is, bullous pemphigoid (BP), pemphigoid gestationis, linear igA disease and mucous membrane pemphigoid, the cause of epidermal impairment is autoimmunity against collagen XVII [29-31]. The autoantibodies are primarily directed against the immunodominant $\mathrm{N}$-terminal of the juxtamembranous NC16a domain [32], which is one of the noncollagenous sequences of collagen XVII's extracellular part [33]. However, collagen XVII's hemidesmosomal ligand BPAG1 can also serve as an autoantigen in BP [34], which is the most frequent pemphigoid; it has an annual incidence varying in different studies from 2.6 to 42.8 per million population [35]. It usually affects the elderly, and both genders are similarly affected. Clinically, it is characterized by tense blisters, variably associated with severe itching.

Interestingly, robust statistical associations between BP and neurological disorders have been repeatedly published, particularly in relation to dementia and cerebrovascular disease (Table 1). Foureur et al. [36] found neurological disorders in $65 \%(n=30 / 46)$ of consecutive day-unit patients with BP, chief amongst which were senile dementia and cerebral stroke. Likewise, Cordel et al. [37] found that $36 \%$
( $n=123 / 341)$ of BP patients from French dermatology departments had a neurological disorder: $55 \%$ of these were dementia, primarily Alzheimer's disease followed by vascular dementia, and $42 \%$ were cerebral stroke. These findings were repeated by Jedlickova et al. [38]. Their analysis showed that psychoneurological disease, again primarily cerebral stroke and dementia, was found in $42.7 \%$ of $89 \mathrm{BP}$ patients but only in $19.1 \%$ of controls. Similar figures were reported by Taghipour et al. [39]: at least one neurological disease was present in $46 \%$ of 90 consecutive BP patients from an immunobullous referral centre, as compared to $11 \%$ in controls. Identically, a significant association with BP was found for cerebrovascular disease and dementia. Dementia, or severe cognitive impairment, has since been consistently reported in association with BP in three more studies [40-42] and a case report [43]. What is more, a study of 138 elderly subjects with no dermatological symptoms showed that the presence of anticollagen XVII antibodies in the serum was significantly correlated with a mini-mental test score of under 24/30, that is, the cut-off score for dementia [44].

Also, multiple sclerosis and Parkinson's disease have been associated with bullous pemphigoid. A retrospective study of the discharge records of all hospitalized patients in a region in northern Italy supported an association between bullous pemphigoid, multiple sclerosis, and Parkinson's disease [45]. In line with these findings, the literature reports several cases of bullous pemphigoid developing in patients with multiple sclerosis [46-48] and at least one in a patient with Parkinson's disease [49]. The association of Parkinson's disease with bullous pemphigoid has been subsequently reported in epidemiological studies others by as well [37, 40-42]. There are also case reports of unilateral BP on the paralyzed side of hemiplegic patients $[36,50,51]$.

Psychiatric morbidity may also be associated with BP [52]. Bastuji-Garin found that unipolar or bipolar mood disorders and the use of psycholeptics, particularly neuroleptics, were a risk factor for BP in the elderly $[41,53]$. One large study has also associated schizophrenia with BP in females [42].

Although BP usually affects people over 65 years of age, cases among younger people are not unheard of. Interestingly, a retrospective study of $74 \mathrm{BP}$ patients under the age of 60 found neurological disorders in 12 and use of psychiatric drugs in 33 cases [54] (not included in Table 1 due to age difference of cases as compared to the other studies).

In light of the association between BP and neurological impairment, it is notable that neurological symptoms are not associated with junctional epidermolysis bullosa [55]. This suggests that collagen XVII impairment in itself does not explain the neurodermatological symptoms but, rather, the pathological autoinflammatory reaction against collagen XVII, feasibly by increasing vascular permeability and favouring transendothelial migration of inflammatory cells. In fact, it has recently been revealed that collagen XVII itself has an important role in regulating inflammatory chemotaxis: depending on the type of inflammatory stimuli, the expression level of collagen XVII can have either an enhancing or suppressing effect on IL-8, a proinflammatory chemokine [56]. 
TABLE 1: Epidemiological studies linking bullous pemphigoid and neurological morbidity.

\begin{tabular}{|c|c|c|c|c|}
\hline Reference & $\begin{array}{c}\text { Country of } \\
\text { study }\end{array}$ & Type of study & $\begin{array}{l}\text { Number of BP } \\
\text { cases in study }\end{array}$ & Neurological disorders associated to BP \\
\hline Foureur et al., 2001 [36] & France & Retrospective case control & 46 & $\begin{array}{l}\text { Senile dementia/Alzheimer } \\
\text { Cerebral stroke }\end{array}$ \\
\hline Stinco et al., 2005 [45] & Italy & Retrospective & 238 & $\begin{array}{l}\text { Multiple sclerosis } \\
\text { Parkinson's disease }\end{array}$ \\
\hline Cordel et al., 2007 [37] & France & Retrospective & 341 & $\begin{array}{l}\text { Dementia } \\
\text { Cerebral stroke } \\
\text { Parkinson's disease or parkinsonism }\end{array}$ \\
\hline Jedlickova et al., 2010 [38] & Czech Republic & Retrospective case control & 89 & $\begin{array}{l}\text { Dementia } \\
\text { Cerebral stroke }\end{array}$ \\
\hline Taghipour et al., 2010 [39] & UK & Retrospective case control & 90 & $\begin{array}{l}\text { Cerebrovascular disease } \\
\text { Dementia }\end{array}$ \\
\hline Langan et al., 2011 [40] & UK & $\begin{array}{l}\text { Retrospective population } \\
\text { based case-control }\end{array}$ & 868 & $\begin{array}{l}\text { Dementia } \\
\text { Parkinson's disease } \\
\text { Stroke } \\
\text { Epilepsy }\end{array}$ \\
\hline Bastuji-Garin et al., 2011 [41] & France & Prospective case control & 201 & $\begin{array}{l}\text { Severe cognitive impairment }(\text { MMSE }<17) \\
\text { Parkinsons' disease } \\
\text { Uni- or bipolar disorder } \\
\text { Long-term neuroleptic drug use }\end{array}$ \\
\hline Chen et al., 2011 [42] & Taiwan & $\begin{array}{l}\text { Retrospective population } \\
\text { based case control }\end{array}$ & 3485 & $\begin{array}{l}\text { Dementia } \\
\text { Stroke } \\
\text { Schizophrenia } \\
\text { Epilepsy } \\
\text { Parkinson's disease }\end{array}$ \\
\hline
\end{tabular}

\section{The Possible Role of Collagen XVII as a Common Antigen in Neurological and Immunobullous Skin Disorders}

The fact that collagen XVII is present in human brain tissue raises the possibility of collagen XVII having a role in neurological disorders, particularly in association with subsequent BP. Interestingly, BPAG1, the other antigen targeted in BP, also has variants that are expressed in the nervous system [57-59] and could thus also serve as an autoantigen in the BP-associated neurological disorders. Indeed, antibodies in the serum of patients with both BP and various neurological diseases have been shown to recognize both a $180 \mathrm{kDa}$ and a $230 \mathrm{kDa}$ protein corresponding to collagen XVII and BPAG1, respectively, in mouse and human brain extract $[57,60]$ and human epidermal extract $[61,62]$. What the relative significance of these two antigens is in neurological disease is unclear: previous studies have revealed only a low frequency of reactivity in the immunoblotting of the cerebrospinal fluid of MS patients (without BP) against BPAG1 [58, 62]. Also, in a study of collagen XVII and BPAG1 autoantibodies in the serum of 337 individuals with no signs of BP [63], of the 25 found to be positive, 5 had neurologic diseases listed in their medical records; in all but one case the amount of collagen XVII antibodies was greater than the amount for BPAG1 (correspondence [64]). On the other hand, Soni et al. [65] found evidence of neither collagen XVII nor BPAG1 antibodies in a case of autoimmune encephalopathy with BP.
In any case, when both BP and neurological disorder are present, neurological disease usually precedes BP $[40,60]$ by months to years $[37,45]$. This supports the idea that neuronal antigen exposure, conceivably via a compromised blood-brain barrier, is causatively involved in subsequent development of BP. In light of this, the hypothesis of immunoglobulin-mediated neurodegeneration in Alzheimer's disease [66] is intriguing, as dementia is the disorder most consistently associated with BP. This hypothesis involves an age-related compromise of the blood-brain barrier [67] and loss of the "immunological privilege" of the brain. In a murine model of senescence, vascular permeability to the brain has been shown to be particularly prevalent in the hippocampal region [68], where the present author et al. have shown strong collagen XVII expression $[25,26]$, and which is a well-recognized predilection area for Alzheimer's disease- (AD-)related lesions [69]. It is also interesting that our previous results, albeit based on samples from a single brain (male, 68 years of age at death), show that collagen XVII expression was confined to lipofuscin [27], as oxidative stress is intimately associated with the aging process and $\mathrm{AD}[70]$. Lipofuscin is primarily composed of nondegradable, oxidatively modified macromolecule residues which largely originate from autophagocytosed mitochondria [71], the organelle most affected by the oxidative damage caused by free radicals emanating from the respiratory processes [72]. Lipofuscin has usually been considered waste material, the accumulation of which has a detrimental effect on various cellular functions 
[73], although this view has been questioned as the variability of lipopigments and sytosolic degradation pathways has been expounded [74]. It has also been suggested that lipofuscin actually benefits the neuron by incorporating potentially damaging metabolites [75]. However, it is worth considering that in a younger brain the intracellular location of collagen XVII could be different, as lipofuscin accumulates in the aging neuron; thus the findings concerning the intraneuronal localization of collagen XVII must be viewed as preliminary.

The other condition most frequently reported in association with $\mathrm{BP}$ is cerebrovascular disease, or stroke (Table 1). Of course, etiopathogenetically, this is not a neuronal disease but vascular in origin. Therefore, it is interesting that in contrast with neurological disease in general, stroke has been shown to often occur after the onset of BP [76]. This could be explained by the fact that the inflammatory state present in BP is not confined to the skin but also involves vascular endothelium [77], as does the pathogenesis of atherosclerosis, atheroma plaque rupture, and thrombosis [78]. Also, the inflammatory response in BP involves raised levels of eosinophils not only in the skin lesions but also in peripheral blood [79] and it has been shown that eosinophil granulocytes are an important source of tissue factor, the initiator of blood coagulation, in human blood [ 80,81$]$. In addition, there is some evidence that antiphospholipid antibodies are present in the serum of BP patients [82]. Thus, the BP-associated inflammation, together with the hypercoagulable state associated with eosinophilia and antiphospholipid antibodies, could exacerbate preexisting atherosclerosis and promote thrombosis and stroke [76].

In terms of inflammation, the findings linking affective disorder and schizophrenia with BP [41, 42] are interesting, as there is evidence of upregulation of immune response genes in these disorders [83]. In fact, for schizophrenia, a neuroimmune hypothesis has been debated for decades [84], most recently in terms of NMDA-receptor autoimmunity [85, 86]. Although the current consensus concerning the inflammatory etiology of schizophrenia involves the idea of a longlasting consequence of an infective-immune challenge during early brain development, numerous other explanations have been offered, including autoimmunity towards certain brain structures [87], particularly in the hippocampus [88]. However, as inflammation is also closely linked with behavioral parameters such as exercise, alcohol abuse, and smoking, as well as with medical conditions including coronary artery disease, obesity, and insulin resistance [89], interpreting the inflammatory findings in psychiatric disease is exceedingly complex. Added to this is the fact that collagen XVII itself has now been shown to have a dynamic role in inflammatory responsivity [56]; whether this can in any way be linked to BPassociated neuropsychiatric morbidity remains to be seen.

All in all, the findings presented previously support the idea of collagen XVII being a worthwhile focus of study in the area of neuroimmunology. Although the statistical studies linking BP with neurological disorders are robust, further biological studies are needed to answer questions relating to both the physiological and pathogenetic roles of collagen XVII in the CNS.

\section{Acknowledgments}

Päivi Toivonen, MD, and Ann Seppänen BA, M.Ed, are acknowledged for critical reading of the paper.

\section{References}

[1] J. Myllyharju and K. I. Kivirikko, "Collagens, modifying enzymes and their mutations in humans, flies and worms," Trends in Genetics, vol. 20, no. 1, pp. 33-43, 2004.

[2] K. E. Kadler, C. Baldock, J. Bella, and R. P. Boot-Handford, “Collagens at a glance," Journal of Cell Science, vol. 120, part 12, pp. 1955-1958, 2007.

[3] J. Sajanti, A.-S. Björkstrand, S. Finnilä, E. Heikkinen, J. Peltonen, and K. Majamaa, "Increase of collagen synthesis and deposition in the arachnoid and the dura following subarachnoid hemorrhage in the rat," Biochimica et Biophysica Acta, vol. 1454, no. 3, pp. 209-216, 1999.

[4] F. L. Cardoso, D. Brites, and M. A. Brito, "Looking at the bloodbrain barrier: molecular anatomy and possible investigation approaches," Brain Research Reviews, vol. 64, no. 2, pp. 328-363, 2010.

[5] M. A. Fox, "Novel roles for collagens in wiring the vertebrate nervous system," Current Opinion in Cell Biology, vol. 20, no. 5, pp. 508-513, 2008.

[6] T. Hubert, S. Grimal, P. Carroll, and A. Fichard-Carroll, "Collagens in the developing and diseased nervous system," Cellular and Molecular Life Sciences, vol. 66, no. 7, pp. 1223-1238, 2009.

[7] A. L. Sertié, V. Sossi, A. A. Camargo, M. Zatz, C. Brahe, and M. R. Passos-Bueno, "Collagen XVIII, containing an endogenous inhibitor of angiogenesis and tumor growth, plays a critical role in the maintenance of retinal structure and in neural tube closure (Knobloch syndrome)," Human Molecular Genetics, vol. 9, no. 13, pp. 2051-2058, 2000.

[8] S. A. Ali, I. S. Pappas, and J. G. Parnavelas, "Collagen type IV promotes the differentiation of neuronal progenitors and inhibits astroglial differentiation in cortical cell cultures," Developmental Brain Research, vol. 110, no. 1, pp. 31-38, 1998.

[9] V. A. Schneider and M. Granato, "The myotomal diwanka (lh3) glycosyltransferase and type XVIII collagen are critical for motor growth cone migration," Neuron, vol. 50, no. 5, pp. 683695, 2006.

[10] T. Xiao and H. Baier, "Lamina-specific axonal projections in the zebrafish tectum require the type IV collagen Dragnet," Nature Neuroscience, vol. 10, no. 12, pp. 1529-1537, 2007.

[11] M. A. Fox, J. R. Sanes, D.-B. Borza et al., "Distinct target-derived signals organize formation, maturation, and maintenance of motor nerve terminals," Cell, vol. 129, no. 1, pp. 179-193, 2007.

[12] D. S. Heffron, G. E. Landreth, I. S. Samuels, and J. W. Mandell, "Brain-specific deletion of extracellular signal-regulated kinase 2 mitogen-activated protein kinase leads to aberrant cortical collagen deposition," American Journal of Pathology, vol. 175, no. 6, pp. 2586-2599, 2009.

[13] N. M. Hooper, E. H. Karran, and A. J. Turner, "Membrane protein secretases," Biochemical Journal, vol. 321, part 2, pp. 265279, 1997.

[14] C.-W. Franzke, K. Tasanen, H. Schumann, and L. BrucknerTuderman, "Collagenous transmembrane proteins: collagen XVII as a prototype," Matrix Biology, vol. 22, no. 4, pp. 299-309, 2003. 
[15] C.-W. Franzke, P. Bruckner, and L. Bruckner-Tuderman, "Collagenous transmembrane proteins: recent insights into biology and pathology," Journal of Biological Chemistry, vol. 280, no. 6 , pp. 4005-4008, 2005.

[16] G. J. Giudice, D. J. Emery, and L. A. Diaz, "Cloning and primary structural analysis of the bullous pemphigoid autoantigen BP180," Journal of Investigative Dermatology, vol. 99, no. 3, pp. 243-250, 1992.

[17] S. B. Hopkinson, K. Findlay, G. W. DeHart, and J. C. R. Jones, "Interaction of BP180 (type XVII collagen) and CC6 integrin is necessary for stabilization of hemidesmosome structure," Journal of Investigative Dermatology, vol. 111, no. 6, pp. 10151022, 1998.

[18] S. B. Hopkinson and J. C. R. Jones, "The N terminus of the transmembrane protein $\mathrm{BP} 180$ interacts with the $\mathrm{N}$ - terminal domain of BP230, thereby mediating keratin cytoskeleton anchorage to the cell surface at the site of the hemidesmosome," Molecular Biology of the Cell, vol. 11, no. 1, pp. 277-286, 2000.

[19] S. B. Hopkinson, S. E. Baker, and J. C. R. Jones, "Molecular genetic studies of a human epidermal autoantigen (the 180$\mathrm{kD}$ bullous pemphigoid antigen/BP180): identification of functionally important sequences within the BP180 molecule and evidence for an interaction between BP180 and $\alpha 6$ integrin," Journal of Cell Biology, vol. 130, no. 1, pp. 117-125, 1995.

[20] C.-W. Franzke, L. Bruckner-Tuderman, and C. P. Blobel, "Shedding of collagen XVII/BP180 in skin depends on both ADAM10 and ADAM9," Journal of Biological Chemistry, vol. 284, no. 35, pp. 23386-23396, 2009.

[21] C.-W. Franzke, K. Tasanen, H. Schäcke et al., "Transmembrane collagen XVII, an epithelial adhesion protein, is shed from the cell surface by ADAMS," EMBO Journal, vol. 21, no. 19, pp. 50265035, 2002.

[22] H. Schäcke, H. Schumann, N. Hammami-Hauasli, M. Raghunath, and L. Bruckner-Tuderman, "Two forms of collagen XVII in keratinocytes: a full-length transmembrane protein and a soluble ectodomain," Journal of Biological Chemistry, vol. 273, no. 40, pp. 25937-25943, 1998.

[23] K. Tasanen, L. Tunggal, G. Chometon, L. Bruckner-Tuderman, and M. Aumailley, "Keratinocytes from patients lacking collagen XVII display a migratory phenotype," American Journal of Pathology, vol. 164, no. 6, pp. 2027-2038, 2004.

[24] T. Claudepierre, M. K. Manglapus, N. Marengi et al., "Collagen XVII and BP AG1 expression in the retina: evidence for an anchoring complex in the central nervous system," Journal of Comparative Neurology, vol. 487, no. 2, pp. 190-203, 2005.

[25] A. Seppänen, H. Autio-Harmainen, I. Alafuzoff et al., "Collagen XVII is expressed in human CNS neurons," Matrix Biology, vol. 25, no. 3, pp. 185-188, 2006.

[26] A. Seppänen, T. Suuronen, S. C. Hofmann, K. Majamaa, and I. Alafuzoff, "Distribution of collagen XVII in the human brain," Brain Research, vol. 1158, no. 1, pp. 50-56, 2007.

[27] A. Seppänen, R. Miettinen, and I. Alafuzoff, "Neuronal collagen XVII is localized to lipofuscin granules," NeuroReport, vol. 21, no. 17, pp. 1090-1094, 2010.

[28] A. M. Powell, Y. Sakuma-Oyama, N. Oyama, and M. M. Black, "Collagen XVII/BP180: a collagenous transmembrane protein and component of the dermoepidermal anchoring complex," Clinical and Experimental Dermatology, vol. 30, no. 6, pp. 682687, 2005.

[29] M. Kasperkiewicz, D. Zillikens, and E. Schmidt, "Pemphigoid diseases: pathogenesis, diagnosis, and treatment," Autoimmunity, vol. 45, no. 1, pp. 55-70, 2012.
[30] Z. Liu, L. A. Diaz, J. L. Troy et al., "A passive transfer model of the organ-specific autoimmune disease, bullous pemphigoid, using antibodies generated against the hemidesmosomal antigen, BP180," Journal of Clinical Investigation, vol. 92, no. 5, pp. 2480 2488, 1993.

[31] L. Huilaja, K. Makikallo, R. Sormunen, J. Lohi, T. Hurskainen, and K. Tasanen, "Gestational pemphigoid: placental morphology and function," Acta Dermato-Venereologica, vol. 93, no. 1, pp. 33-38, 2013.

[32] D. Zillikens, P. A. Rose, S. D. Balding et al., “Tight clustering of extracellular BP180 epitopes recognized by bullous pemphigoid autoantibodies," Journal of Investigative Dermatology, vol. 109, no. 4, pp. 573-579, 1997.

[33] L. Leighty, N. Li, L. A. Diaz, and Z. Liu, "Experimental models for the autoimmune and inflammatory blistering disease, Bullous pemphigoid," Archives of Dermatological Research, vol. 299, no. 9, pp. 417-422, 2007.

[34] M. Kasperkiewicz and D. Zillikens, "The pathophysiology of bullous pemphigoid," Clinical Reviews in Allergy and Immunology, vol. 33, no. 1-2, pp. 67-77, 2007.

[35] B. Cortés, G. Marazza, L. Naldi, C. Combescure, and L. Borradori, "Mortality of bullous pemphigoid in Switzerland: a prospective study," British Journal of Dermatology, vol. 165, no. 2, pp. 368-374, 2011.

[36] N. Foureur, V. Descamps, B. Lebrun-Vignes et al., "Bullous pemphigoid in a leg affected with hemiparesia: a possible relation of neurological diseases with bullous pemphigoid?" European Journal of Dermatology, vol. 11, no. 3, pp. 230-233, 2001.

[37] N. Cordel, O. Chosidow, M.-F. Hellot et al., "Neurological disorders in patients with bullous pemphigoid," Dermatology, vol. 215, no. 3, pp. 187-191, 2007.

[38] H. Jedlickova, M. Hlubinka, T. Pavlik, V. Semradova, E. Budinska, and Z. Vlasin, "Bullous pemphigoid and internal diseasesa case-control study," European Journal of Dermatology, vol. 20, no. 1, pp. 96-101, 2010.

[39] K. Taghipour, C.-C. Chi, A. Vincent, R. W. Groves, V. Venning, and F. Wojnarowska, "The association of bullous pemphigoid with cerebrovascular disease and dementia: a case-control study," Archives of Dermatology, vol. 146, no. 11, pp. 1251-1254, 2010.

[40] S. M. Langan, R. W. Groves, and J. West, "The relationship between neurological disease and bullous pemphigoid: a population-based case-control study," Journal of Investigative Dermatology, vol. 131, no. 3, pp. 631-636, 2011.

[41] S. Bastuji-Garin, P. Joly, P. Lemordant et al., "Risk factors for bullous pemphigoid in the elderly: a prospective case-control study," Journal of Investigative Dermatology, vol. 131, no. 3, pp. 637-643, 2011.

[42] Y. J. Chen, C. Y. Wu, M. W. Lin et al., "Comorbidity profiles among patients with bullous pemphigoid: a nationwide population-based study," British Journal of Dermatology, vol. 165, no. 3, pp. 593-599, 2011.

[43] N. Kanda, Y. Soga, M. Meguro et al., "Discovery of a patient with strongly suspected bullous pemphigoid in a ward by oral health care providers," International journal of dental hygiene, vol. 9, no. 2, pp. 159-162, 2011.

[44] N. Foureur, S. Mignot, P. Senet et al., "Correlation between the presence of type-2 anti-pemphigoid antibodies and dementia in elderly subjects with no clinical signs of pemphigoid," Annales de Dermatologie et de Venereologie, vol. 133, no. 5, part 1, pp. 439443, 2006. 
[45] G. Stinco, R. Codutti, M. Scarbolo, F. Valent, and P. Patrone, "A retrospective epidemiological study on the association of bullous pemphigoid and neurological diseases," Acta DermatoVenereologica, vol. 85, no. 2, pp. 136-139, 2005.

[46] G. Stinco, P. Mattighello, M. Zanchi, and P. Patrone, "Multiple sclerosis and bullous pemphigoid: a casual association or a pathogenetic correlation?" European Journal of Dermatology, vol. 12, no. 2, pp. 186-188, 2002.

[47] G. Kirtschig, V. M. Walkden, V. A. Venning, and F. Wojnarowska, "Bullous pemphigoid and multiple sclerosis: a report of three cases and review of the literature," Clinical and Experimental Dermatology, vol. 20, no. 6, pp. 449-453, 1995.

[48] S. Simjee, A. Konqui, and A. R. Ahmed, "Multiple sclerosis and bullous pemphigoid," Dermatologica, vol. 170, no. 2, pp. 86-89, 1985.

[49] A. Forschner, A. Ulmer, G. Rassner, and G. Fierlbeck, "Bullous pemphigoid in a patient with Parkinson's disease," European Journal of Dermatology, vol. 12, no. 6, p. 615, 2002.

[50] C. C. Long, L. R. Lever, and R. Marks, "Unilateral bullous pemphigoid in a hemiplegic patient," British Journal of Dermatology, vol. 126, no. 6, pp. 614-616, 1992.

[51] C. B. Bunker and E. Brown, "Unilateral bullous pemphigoid in a hemiplegic patient," British Journal of Dermatology, vol. 129, no. 4, p. 502, 1993.

[52] C. Wijeratne and P. Webster, "Risperidone bullous pemphigoid," American Journal of Psychiatry, vol. 153, no. 5, p. 735, 1996.

[53] S. Bastuji-Garin, P. Joly, C. Picard-Dahan et al., "Drugs associated with bullous pemphigoid: a case-control study," Archives of Dermatology, vol. 132, no. 3, pp. 272-276, 1996.

[54] E. Bourdon-Lanoy, J.-C. Roujeau, P. Joly et al., "Bullous pemphigoid in young patients: a retrospective study of 74 cases," Annales de Dermatologie et de Venereologie, vol. 132, no. 2, pp. 115-122, 2005.

[55] G. Pfendner and A. Lucky, "Junctional epidermolysis bullosa," in GeneReviews, R. Pagon, T. Bird, and C. Dolan, Eds., University of Washington, Seattle, Wash, USA, 2008.

[56] F. Van den Bergh, S. L. Eliason, B. T. Burmeister, and G. J. Giudice, "Collagen XVII (BP180) modulates keratinocyte expression of the proinflammatory chemokine, IL-8," Experimental Dermatology, vol. 21, pp. 605-611, 2012.

[57] L. Li, J. Chen, B. Wang, Y. Yao, and Y. Zuo, "Sera from patients with bullous pemphigoid (BP) associated with neurological diseases recognized BP antigen 1 in the skin and brain," British Journal of Dermatology, vol. 160, no. 6, pp. 1343-1345, 2009.

[58] E. Laffitte, P. R. Burkhard, L. Fontao et al., "Bullous pemphigoid antigen 1 isoforms: potential new target autoantigens in multiple sclerosis?" British Journal of Dermatology, vol. 152, no. 3, pp. 537-540, 2005.

[59] D. A. García-Estévez, G. Peón-Currás, and F. Bal-Nieves, "Bullous pemphigoid and amyotrophic lateral sclerosis," Revista de Neurologia, vol. 47, no. 10, pp. 525-526, 2008.

[60] J. Chen, L. Li, J. Chen et al., "Sera of elderly bullous pemphigoid patients with associated neurological diseases recognize bullous pemphigoid antigens in the human brain," Gerontology, vol. 57, no. 3, pp. 211-216, 2011.

[61] K. Taghipour, C. C. Chi, B. Bhogal, R. W. Groves, V. Venning, and F. Wojnarowska, "Immunopathological characteristics of patients with bullous pemphigoid and neurological disease," Journal of the European Academy of Dermatology and Venereology, 2013.
[62] K. Taghipour, G. Kirtschig, J. Palace, R. W. Groves, V. Venning, and F. Wojnarowska, "The association of multiple sclerosis with bullous pemphigoid: is there a shared antigen response?" Journal of the American Academy of Dermatology, vol. 67, no. 1, pp. 160-161, 2012.

[63] C. N. Wieland, N. I. Comfere, L. E. Gibson, A. L. Weaver, P. K. Krause, and J. A. Murray, "Anti-bullous pemphigoid 180 and 230 antibodies in a sample of unaffected subjects," Archives of Dermatology, vol. 146, no. 1, pp. 21-25, 2010.

[64] N. Foureur, S. Grootenboer-Mignot, and V. Descamps, "Value of the detection of circulating antibodies against BP antigens in unaffected subjects," Archives of Dermatology, vol. 146, no. 7, p. 801, 2010.

[65] A. Soni, S. R. Irani, B. Lang et al., "Immunotherapy: responsive autoimmune encephalopathy associated with bullous pemphigoid," Journal of Neurology, Neurosurgery and Psychiatry, vol. 80, no. 12, pp. 1412-1413, 2009.

[66] C. Bouras, B. M. Riederer, E. Kövari, P. R. Hof, and P. Giannakopoulos, "Humoral immunity in brain aging and Alzheimer's disease," Brain Research Reviews, vol. 48, no. 3, pp. 477-487, 2005.

[67] N. Zeevi, J. Pachter, L. D. McCullough, L. Wolfson, and G. A. Kuchel, "The blood-brain barrier: geriatric relevance of a critical brain-body interface," Journal of the American Geriatrics Society, vol. 58, no. 9, pp. 1749-1757, 2010.

[68] C. Pelegrí, A. M. Canudas, J. del Valle et al., "Increased permeability of blood-brain barrier on the hippocampus of a murine model of senescence," Mechanisms of Ageing and Development, vol. 128, no. 9, pp. 522-528, 2007.

[69] J. Barnes, J. W. Bartlett, L. A. van de Pol et al., "A metaanalysis of hippocampal atrophy rates in Alzheimer's disease," Neurobiology of Aging, vol. 30, no. 11, pp. 1711-1723, 2009.

[70] G. Perry, R. J. Castellani, K. Hirai, and M. A. Smith, "Reactive oxygen species mediate cellular damage in Alzheimer disease," Journal of Alzheimer's Disease, vol. 1, no. 1, pp. 45-55, 1998.

[71] A. Terman and U. T. Brunk, "Oxidative stress, accumulation of biological 'garbage', and aging," Antioxidants and Redox Signaling, vol. 8, no. 1-2, pp. 197-204, 2006.

[72] S. S. Seehafer and D. A. Pearce, "You say lipofuscin, we say ceroid: defining autofluorescent storage material," Neurobiology of Aging, vol. 27, no. 4, pp. 576-588, 2006.

[73] U. T. Brunk and A. Terman, "Lipofuscin: mechanisms of agerelated accumulation and influence on cell function," Free Radical Biology and Medicine, vol. 33, no. 5, pp. 611-619, 2002.

[74] X. Zhu, R. J. Castellani, P. I. Moreira et al., "Hydroxynonenalgenerated crosslinking fluorophore accumulation in Alzheimer disease reveals a dichotomy of protein turnover," Free Radical Biology and Medicine, vol. 52, no. 3, pp. 699-704, 2012.

[75] A. Stojanovic, A. E. Roher, and M. J. Ball, "Quantitative analysis of lipofuscin and neurofibrillary tangles in the hippocampal neurons of Alzheimer disease brains," Dementia, vol. 5, no. 5, pp. 229-233, 1994.

[76] Y.-W. Yang, Y.-H. Chen, S. Xirasagar, and H.-C. Lin, "Increased risk of stroke in patients with bullous pemphigoid: a population-based follow-up study," Stroke, vol. 42, no. 2, pp. 319-323, 2011.

[77] F. Ameglio, L. D’Auria, P. Cordiali-Fei et al., "Bullous pemphigoid and pemphigus vulgaris: correlated behaviour of serum VEGF, sE-selectin and TNF-alpha levels," Journal of Biological Regulators and Homeostatic Agents, vol. 11, no. 4, pp. 148-153, 1997. 
[78] R. Ross and B. Dodet, "Atherosclerosis is an inflammatory disease," American Heart Journal, vol. 138, no. 5, part 2, pp. S419S420, 1999.

[79] A. V. Marzano, A. Tedeschi, E. Berti, D. Fanoni, C. Crosti, and M. Cugno, "Activation of coagulation in bullous pemphigoid and other eosinophil-related inflammatory skin diseases," Clinical and Experimental Immunology, vol. 165, no. 1, pp. 44-50, 2011.

[80] C. Moosbauer, E. Morgenstern, S. L. Cuvelier et al., "Eosinophils are a major intravascular location for tissue factor storage and exposure," Blood, vol. 109, no. 3, pp. 995-1002, 2007.

[81] A. V. Marzano, A. Tedeschi, D. Fanoni et al., "Activation of blood coagulation in bullous pemphigoid: role of eosinophils, and local and systemic implications," British Journal of Dermatology, vol. 160, no. 2, pp. 266-272, 2009.

[82] T. Echigo, M. Hasegawa, M. Inaoki, M. Yamazaki, S. Sato, and K. Takehara, "Antiphospholipid antibodies in patients with autoimmune blistering disease," Journal of the American Academy of Dermatology, vol. 57, no. 3, pp. 397-400, 2007.

[83] C. Konradi, S. E. Sillivan, and H. B. Clay, "Mitochondria, oligodendrocytes and inflammation in bipolar disorder: evidence from transcriptome studies points to intriguing parallels with multiple sclerosis," Neurobiology of Disease, vol. 45, no. 1, pp. 37-47, 2012.

[84] D. Arion, T. Unger, D. A. Lewis, P. Levitt, and K. Mirnics, "Molecular Evidence for Increased Expression of Genes Related to Immune and Chaperone Function in the Prefrontal Cortex in Schizophrenia," Biological Psychiatry, vol. 62, no. 7, pp. 711-721, 2007.

[85] B. R. Lennox, A. J. Coles, and A. Vincent, "Antibody-mediated encephalitis: a treatable cause of schizophrenia," British Journal of Psychiatry, vol. 200, no. 2, pp. 92-94, 2012.

[86] J. Steiner, M. Walter, W. Glanz et al., "Increased prevalence of diverse $N$-Methyl-D-Aspartate glutamate receptor antibodies in patients with an initial diagnosis of schizophrenia: specific relevance of IgG NRla antibodies for distinction from $N$ Methyl-D-Aspartate glutamate receptor encephalitis," JAMA Psychiatry, vol. 70, no. 3, pp. 271-278, 2013.

[87] R. S. Pandey, A. K. Gupta, and U. C. Chaturvedi, "Autoimmune model of schizophrenia with special reference to antibrain antibodies," Biological Psychiatry, vol. 16, no. 12, pp. 1123-1136, 1981.

[88] R. Ganguli, J. S. Brar, K. N. R. Chengappa, Z. W. Yang, V. L. Nimgaonkar, and B. S. Rabin, "Autoimmunity in schizophrenia: a review of recent findings," Annals of Medicine, vol. 25, no. 5, pp. 489-496, 1993.

[89] B. I. Goldstein, D. E. Kemp, J. K. Soczynska, and R. S. McIntyre, "Inflammation and the phenomenology, pathophysiology, comorbidity, and treatment of bipolar disorder: a systematic review of the literature," Journal of Clinical Psychiatry, vol. 70, no. 8, pp. 1078-1090, 2009. 


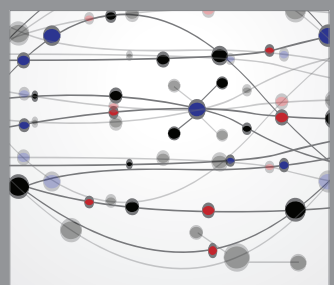

The Scientific World Journal
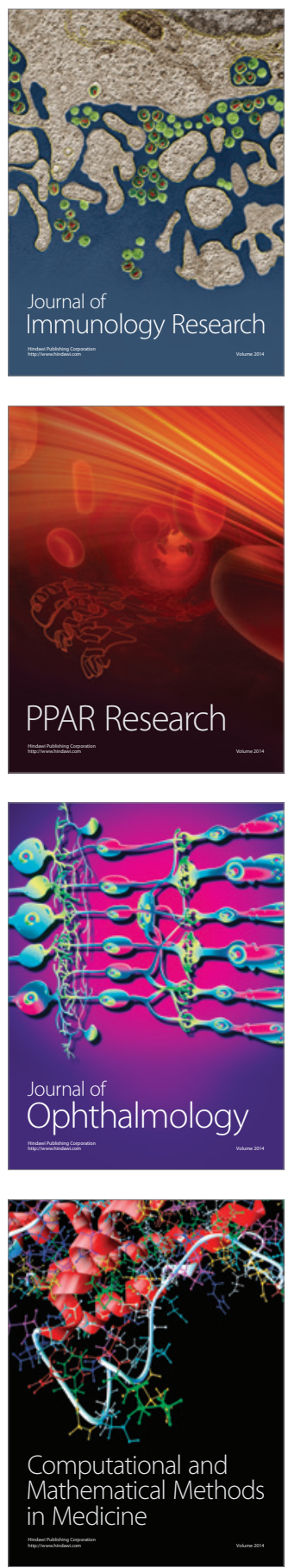

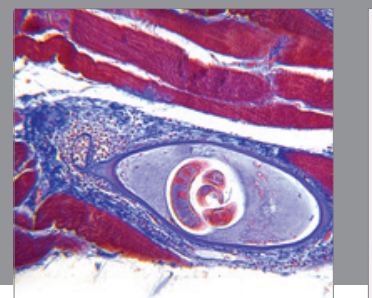

Gastroenterology

Research and Practice
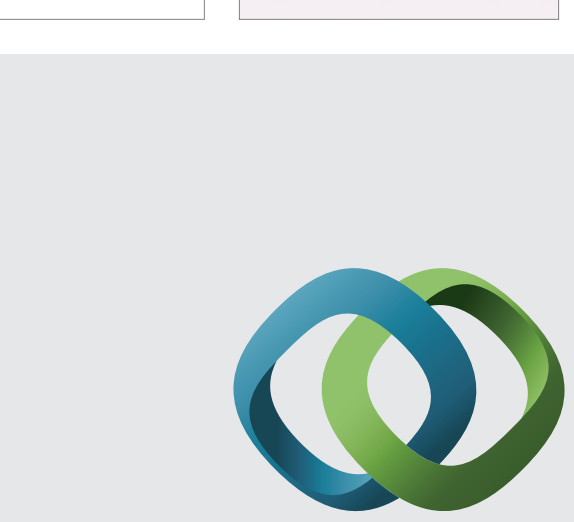

\section{Hindawi}

Submit your manuscripts at

http://www.hindawi.com
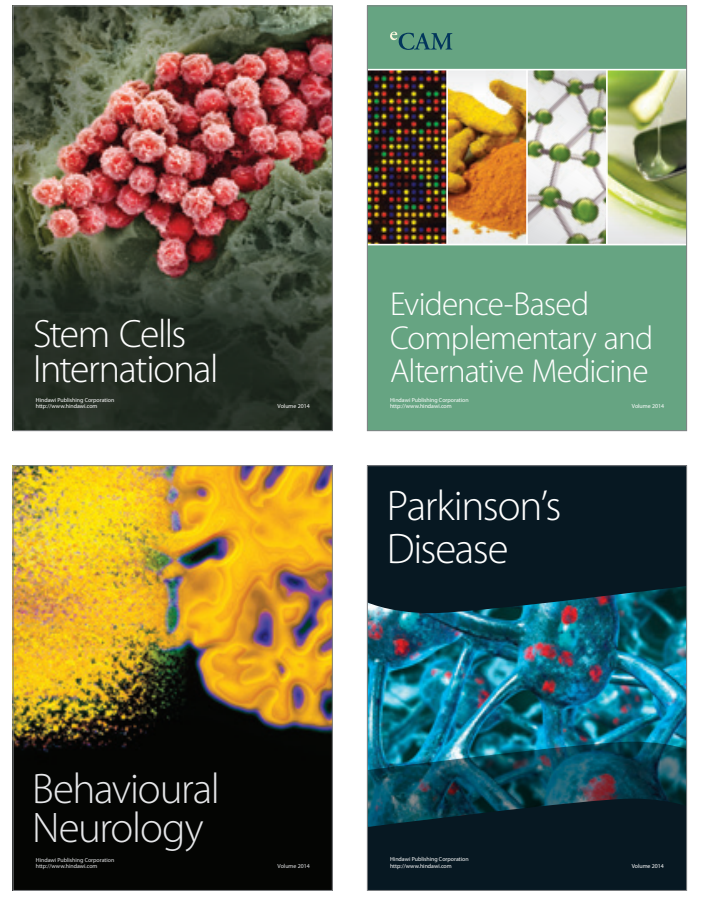
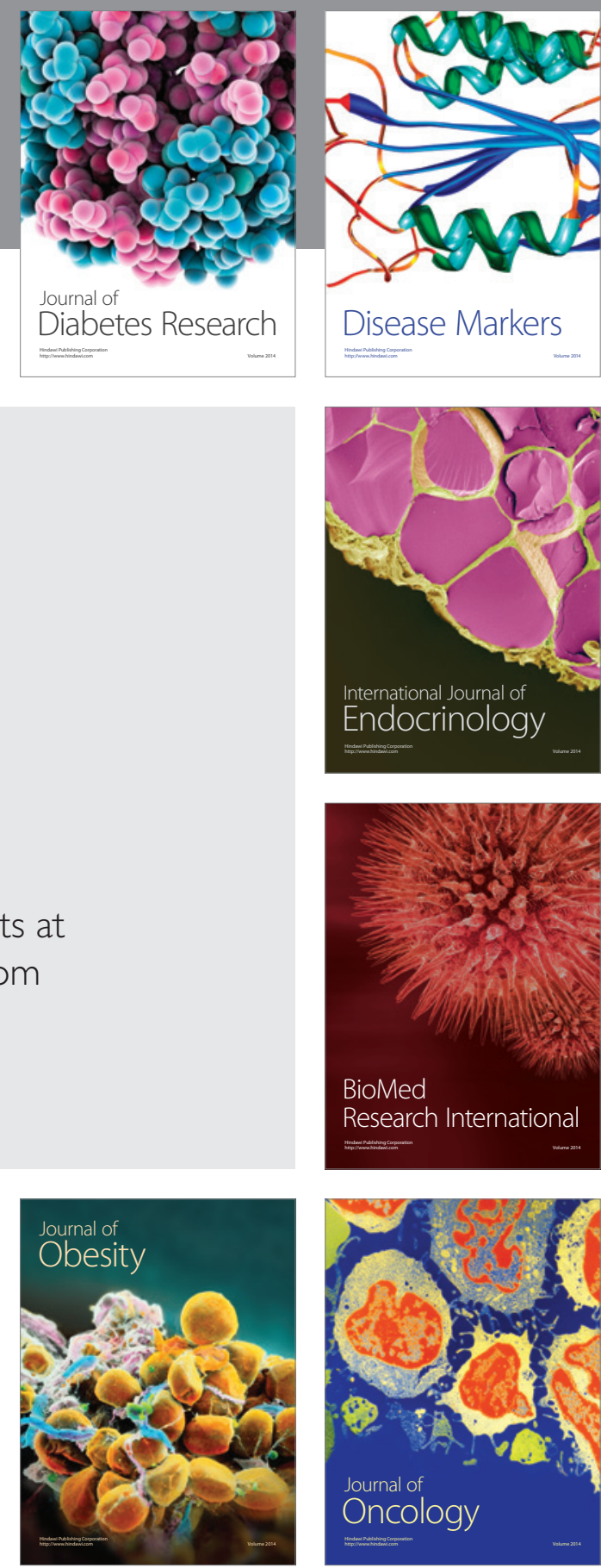

Disease Markers
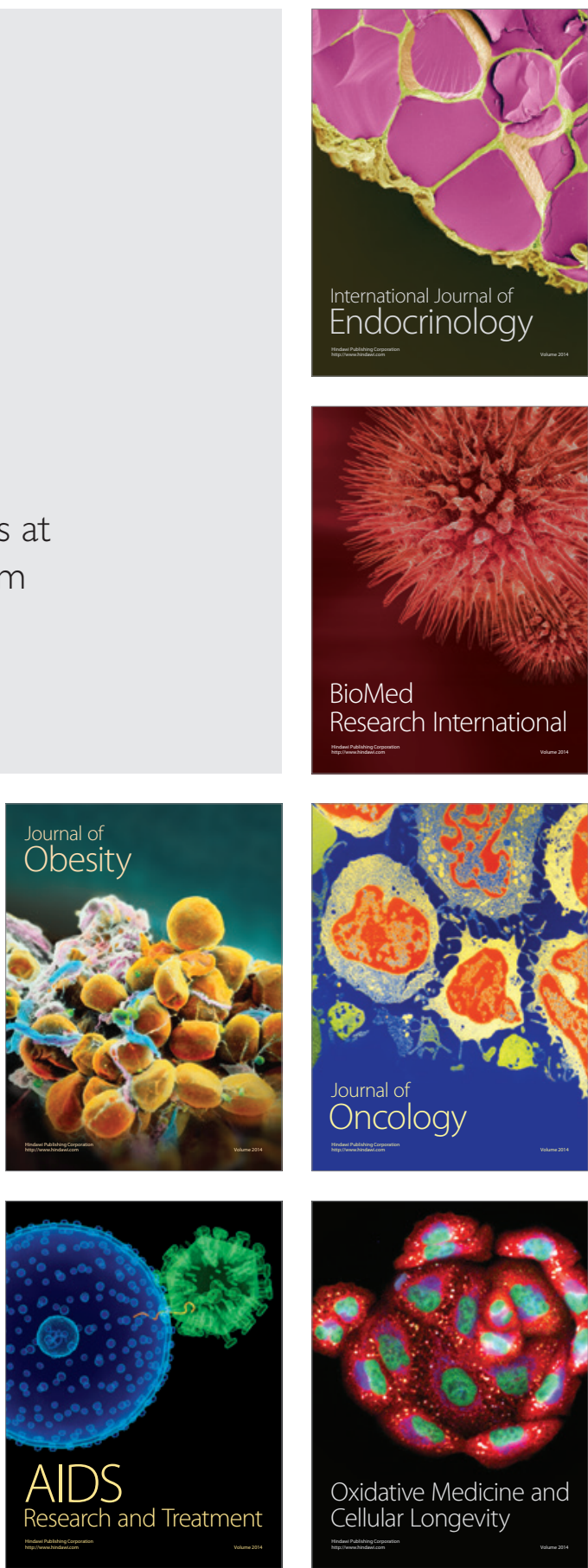